so-called excitotoxic cascade, which ultimately leads to neuronal death, has stimulated a major interest in specific NMDA antagonists that have been found to provide neuronal protection ${ }^{8}$. This led Jevtovic-Todorovic et al. to determine whether or not $\mathrm{N}_{2} \mathrm{O}$ could also act as a neuroprotectant against the neuronal cell death that can be produced by the systemic administration of NMDA (actually they chose to use the racemic NMA on grounds of economy). They found results entirely consistent with their hypothesis. $\mathrm{N}_{2} \mathrm{O}$ acted like an NMDA antagonist, and rats injected with NMA but also breathing $\mathrm{N}_{2} \mathrm{O}$ had many fewer brain lesions than those in the control, air-breathing group.

These observations led inexorably to the next step. Paradoxically, NMDA antagonists can, in addition to their neuroprotectant properties, actually cause neurotoxicity themselves, and the vacuolization of pyramidal neurons in specific regions of the rat cortex has given obvious pause for thought in terms of the clinical use of NMDA blockers as neuroprotectants ${ }^{9}$. Can $\mathrm{N}_{2} \mathrm{O}$ cause such specific lesions? The answer is a worrying 'yes'.

The investigators found that $\mathrm{N}_{2} \mathrm{O}$ caused distinctive lesions in layers III and IV of the posterior cingulate and retrosplenial cortices, identical to those caused by the specific NMDA receptor inhibitor MK-801 and, furthermore, with the same age dependency (young rats are not affected, whereas adult rats are). In addition to adding further weight to the thesis that $\mathrm{N}_{2} \mathrm{O}$ acts on NMDA receptors, these results have wider implications.

Nitrous oxide has been, and remains, a very widely used anesthetic. It has useful analgesic properties, and is often used as a carrier gas so that lower concentrations of the more potent and fat-soluble volatile anesthetics can be used. This practice effectively speeds up recovery. Does the use of $\mathrm{N}_{2} \mathrm{O}$ carry a previously unrecognized risk? This is hard to say. The reason for uncertainty is that, at least in the rat brain, the co-administration of agents that are known to activate or potentiate the $\mathrm{GABA}_{\mathrm{A}}$ receptor, appear to block the neurotoxic effects of NMDA antagonists ${ }^{3,10}$. Because there are good reasons for believing that most general anesthetics exert at least some of their effects on $\mathrm{GABA}_{\mathrm{A}}$ receptors ${ }^{4}$, it might be that, coincidentally, usual anesthetic practice has minimized the potential neurotoxicity of $\mathrm{N}_{2} \mathrm{O}$ because it is usually co-administered with such anesthetics. In addition, of course, the usual caveats about extrapolating results from animal models to humans obviously apply. Nonetheless, when $\mathrm{N}_{2} \mathrm{O}$ is used alone for general anesthesia or, of more concern, when it is used together with another NMDA antagonist such as ketamine, it would be prudent to at least express some concern about the possible neurotoxic side-effects that may result. This will undoubtedly be a subject for future investigations.

1. Paris, I.A. The Life of Sir Humphry Davy (Colburn and Bentley, London, 1831).

2. Davy, $\mathrm{H}$. Some experiments on the gaseous oxide of azote. Nicholson journal 3, 55-56 (1800).

3. Jevtovic-Todorovic, $V$. et al. Nitrous oxide (laughing gas) is an NMDA antagonist, neuroprotectant and neurotoxin. Noture Med. 4, 460-463 (1998).

4. Franks, N.P. \& Lieb, W.R. Molecular and cellular mechanisms of general anaesthesia. Nature 367 607-614 (1994).

5. Franks, N.P. \& Lieb, W.R. An anesthetic-sensitive superfamily of neurotransmitter-gated ion channels. J. Clin. Anesth. 8, S3-S7 (1996)

6. Brockmeyer, D.M. \& Kendig, J.J. Selective effects of ketamine on amino acid-mediated pathways in neonatal rat spinal cord. Br. I. Anaesth. 74, 79-84 (1995)

7. Rang, H.P., Dale, M.M. \& Ritter, I.M. In Pharmacology (Churchill Livingstone, New York, 1995).

8. Small, D.L. \& Buchan, A.M. NMDA antagonists: their role in neuroprotection. Int. Rev. Neurobiol. 40, 137-171 (1997).

9. Olney, J.W., Labruyere, I. \& Price, M.T Pathological changes induced in cerebrocortical neurons by phencyclidine and related drugs. Science 244, 1360-1362 (1989)

10. Olney, J.W. et al. NMDA antagonist neurotoxic ity: mechanism and prevention. Science 254, 1515-1518 (1991).

Biophysics Section

The Blackett Laboratory

Imperial College of Science, Technology and

Medicine

London SW7 2BZ, UK

email:n.franks@ic.ac.uk

\title{
The ticklish brain
}

Some days a good laugh is

hard to find in a neurosurgeon's operating room, but Itzhak Fried and his colleagues (University of California, Los Angeles) got an entertaining surprise recently while they were mapping the brain of a 16 year-old epileptic girl (Nature 391, 650, 1998). Electrical stimulation of a $2 \mathrm{~cm}$ by $2 \mathrm{~cm}$ area in the left superior frontal gyrus (red dots in figure) consistently caused the girl to smile. As the stimulation current was increased, her smile escalated into robust contagious laughter. The stimulated laughter was accompanied by a feeling of merriment.

Systematic electrical stimulation is used to make a functional map of the brain before surgical removal of the seizure-generating region in cases of severe intractable epilepsy. While doctors activate neurons with an electrode, the patient is asked to perform a variety of simple tasks, such as flexing each finger in turn or naming pictures. This procedure helps the surgeons to identify the seizure focus precisely and to avoid removing regions that would impair critical functions such as movement or speech.

The anterior part of the supplementary motor area, where stimulation caused laughter, is involved in the initiation of speech (red, yellow and blue dots in figure), another uniquely human ability. Other brain regions have been connected with laughter in patients whose seizures included laughter or in psychiatric patients, but it is not clear whether 尊 those areas are important for normal laughter. Fried's patient did not laugh during seizures, and stimulation of the seizure focus did not induce laughter. 'We didn't find the laughing center,' Fried emphasizes, 'we just found a node in the network, which is very complex.'

The stimulated laughter did seem to connect to other active areas of the brain, as the girl attributed her laughter to whatever was happening in the room at the time. 'That was very striking,' says Fried, explaining that laughter has at least three parts: the motor program, the feeling of mirth and the cognitive interpretation. The electrical stimulation seemed to provide the first two, and the aspect that was missing, she filled with...the focus of her attention at that time.' If she was looking at a picture of a horse, the horse was funny. She even told her doctors, 'you guys are just so furny...standing around.'

Sandra Aamodt, Nature Neuroscience 